\title{
The Analysis of Project Auditing System
}

\author{
Ashutosh Kumar Yadav \\ Department of Computer Science and Engineering, \\ Sachdeva Institute of Technology, Mathura (Sit Mathura), \\ Dr. A P J Abdul Kalam Technical University, \\ Lucknow, Uttar Pradesh, \\ India. \\ aasho2008@gmail.com
}

\begin{abstract}
During the current trends in IT and Software industry- DevOps, the project management system is mainly responsible to keep track of various projects that are undertaken by the organization and developed with in same premises or geographically locations. The main problem is to develop a system which can handle various task of project management by providing security to project related work while transferring and to provide a communication system for discussion of problems. So this system will run on the virtual private network of organization also secured socket layer is used instead simple hypertext transfer protocol. In project management system the client wants a system that can be used to check the progress that the projects had made which it had distributed among different organization for development. In this arena a central repository (database) should be created which will be maintained by project developing origination on day-to-day basis i.e. the organization must have to update the database on the basis of progress made by them on the given module. The files will be uploaded by assigned user on any particular project about his daily work. There will be various powers to the user which will be provided according to role of a person in particular project. In this system only the status will be changed and nothing will be deleted until any particular project will be completed. Menu of different project will be shown also according to the role. Each user will be provided unique id. for a particular project however user can perform different role simultaneously.
\end{abstract}

Keywords: - Software industry - DevOps, Project Management, Technical Feasibility, Implementation review.

\section{INTRODUCTION}

The bigger picture of project's module is bifurcating it into smaller modules, then these modules are again bifurcated, this is a repetitive process until the smallest unit is identified. This repetitive way of breaking down the modules is called "work breakdown structure". This technique creates a tree, its root is labeled by most activities consist of analysis, design, coding, logic, testing and integration of different module described further. Each node of the tree can be broken down into smaller components that are designated as the child of the node. This work of breaking down can be repeated until each led in the tree is small enough to allow the manager to estimate its size, difficulty, and resources requirements. The goal of a work breaks down structure is to identify all activities that the project must undertake.

The work breaks down is an essential tool that can be used by project coordinator for breaking down larger module into manageable module. once these modules have been identified they can be known as work assignment. Work break down modules can also be put into the set of scheduling process. In down the work, we try to decide which task to be done. In scheduling, we decide the order in which to do these tasks.

\section{PROJECT MANAGEMENT SYSTEM}

Project management system can be broken into seven main modules, these are login module, administration module, project management module, user module, forums, general announcement module and change management module. These modules are further broken into the actual activities which to be done. Administration module is mainly concerned with the administration of projects, so only administrator is authorized to administrative task. User module can be accessed by all the authorized user of any particular project. Forum module is to be used only for discussion. Of these modules login module is most important because of the security concerned with this module. Project management module is little complex.

\section{FEASIBILITY STUDY}

The feasibility study proposed a solution based on the necessities of requirement of the project. Report is created

ISSN: 2582-4104 
Journal of trends in Computer Science and Smart technology (TCSST) (2020)

Vol.02/ No. 04

Pages: 211-219

https://www.irojournals.com/tcsst/

DOI: https://doi.org/10.36548/jtcsst.2020.4.006

during the phase of feasibility study that is a recommendation for solution. It helps in figuring out the cost effectiveness of a proposed system.

The feasibility study has been performing to validate if the proposed system is worth to implement. After performing an initial Investigation, gathering and interpretation of data and details concerning the project, a Feasibility Check is done which involves a series of steps to check the Technical, Financial and Operational feasibilities.

Profit and benefit are the major criteria to be validated before opposing solution for any proposed system.

Below of the proposed solutions

A. By bifurcating till the basic data should made available by the system.

B. Requirement of New Computing system will be required.

C. End to End description of requirement should be provided that which task will be done manually and what needs to handle by the automated system.

\subsection{Economical Feasibility:}

The feasibility has been most importance as an offset, other feasibilities are used of costs affect then management decisions. This Investigation typically involves a prize/ benefits analyzes of the project, its helping managements determine the checked, cost, and benefits associated with a project before financial manpower are allocated. It also serves as an independent project Investigation and enhances project reliability-its helping decision-making determine the economic benefits to the organization that the proposed project will be done.

The intangible benefits include time saved for message passing, reduced cost of communication and security.

\subsection{Technical Feasibility:}

Technical feasibility is related to the software and equipment required in the design for creating a new system. Technical feasibility is a study of purpose, performance and constraints that may affect the ability to achieve an acceptable system. During technical analysis, the analyst evaluates the technical merits of the system, parallel collecting additional information about performance, reliable, maintainable and productivities. Technical feasibility is the hardest target to assess.

In this study it is determined whether the existing equipment's, s/w technology and available personnel are sufficient. The machines used are sufficient and are available at the organization. The software used is JSP, TOMCAT and MS ACCESS all of which are available at the organization.

\subsection{Behavioral Feasibility:}

Behavioral/operational feasibility is degree of system representation to a common world. its criteria to measure the urgency of problem or the acceptability to answer. Operational feasibility helps us to calculate manpower requirement for project. it provides estimation regarding the operation once the system will be installed.

As this project is carried under very experienced guide who is able the answer most of the queries of the trainees so all the trainees are completely satisfied. An Application can be technically good but unsuccessful execution produce forecasted benefit, due to the organization having lack of professional, so the user should provide technical training. Duplicity can be remove as the system will fully automated. The users of this project will get a new and more secure way of message passing and thus they will also be satisfied.

\section{SOFTWARE ENGINEERING PARADIGM}

Design Programming Maintenance in the Project design the method and operational modules are described like screen layouts, user field, Registration field, Administrator field, Logic, The guideline of process figure and documentation. It will be describing the new system as a collection of modules or sub systems of output.

ISSN: 2582-4104 
Journal of trends in Computer Science and Smart technology (TCSST) (2020)

Vol.02/ No. 04

Pages: 211-219

https://www.irojournals.com/tcsst/

DOI: https://doi.org/10.36548/jtcsst.2020.4.006

The Module design initial stage input the requirements identified that after approved the document. Its requirement, a set of more design components will be composed as a result of interviews, workshops, and/or prototype efforts (4).

There are some types of testing:

- $\quad$ Bug testing the failed scenarios, including bug tracking

- $\quad$ Path variable testing

- $\quad$ Database set testing

- $\quad$ Unit testing

- $\quad$ System required testing

- $\quad$ User acceptance testing

- $\quad$ Software performance testing

Work breakdown module (6)

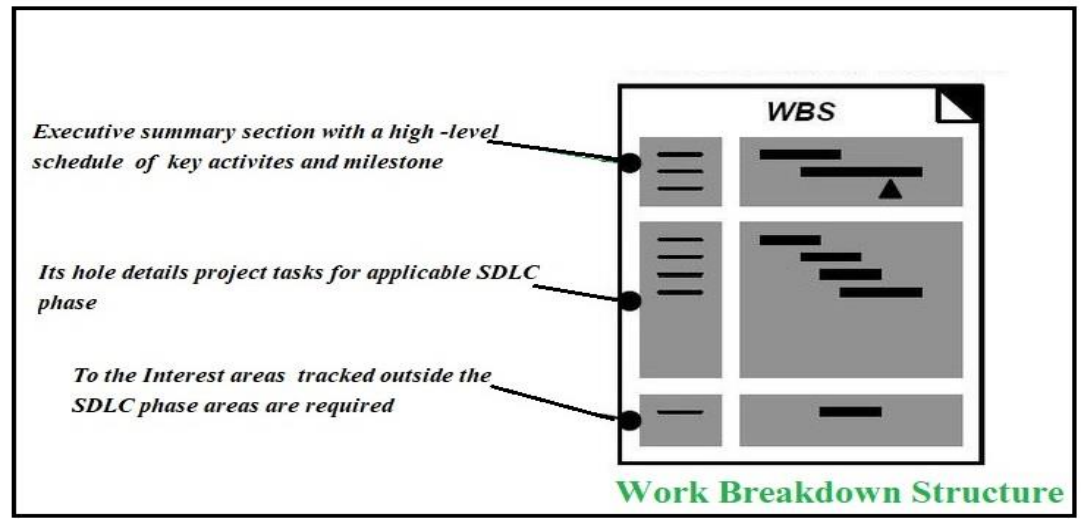

Figure 1

\section{SOFTWARE ENGINEERING PARADIGM APPLIED}

The software of a methodical, disciplined, excellent approach to the development, operation and maintain the software; that is the application of engineering to software. It is a set of rules that include consists tools and techniques used for developing and maintaining software. For solving problems in a system there must be a development strategy that encompasses the process, methods tools and generic phases used for solving the problem. This development scenario is assign as process modules or a software-engineering chart, it is a methodology to resolve the problem industry setting, software engineer or team of engineers must include a development plan of action that surrounds the process, methods and tool layers and generic phases. The selection of Process model is done on the basis of nature of project and application, the methods and tools to be used and the control and deliverables that are required.

The software is complicated system get and resolve in the same given time period. As development progresses the product requirements of system also change.

While creating a Software, based on user needs designs are created, now these designs are converted to machine executable languages that can be interpreted by the computer and at last the software is tested and delivered to the customers. The evolutionary process modules are constants. Them to described in a proper manner that enables development of increasingly more complex version of software. The process model chosen to be implemented for development of this particular system is PROTOTYPE MODEL.

Advantages of prototype model: -

1. It provides better understanding of customer's need.

2. It is useful in the development of very large system.

3. It is useful to solidify user requirement.

4. It is helps to technically audit the technical problems identify with a product development teams. 
Journal of trends in Computer Science and Smart technology (TCSST) (2020)

Vol.02/ No. 04

Pages: 211-219

https://www.irojournals.com/tcsst/

DOI: https://doi.org/10.36548/jtcsst.2020.4.006

\section{SOFTWARE REQUIREMENT SPECIFICATIONS}

The most important step in the development of any software is the analysis which should satisfied by it. A deep understanding of these requirements is required for the successful creation and implementation of software.

- Working correct

- Glaring

- Complete the project

- Compatible

- Stability

- Modifiable project

- Tracking project

The software requirement specification provides the modules and objective the software. it essential complete understanding of the functionally that software much perform.

\section{SCOPE OF PLAN}

The main problem faced during the project, which is developed in different workstation is to maintain communication between geographically distributed workstations. At present, there are many mode of communication, but we have to develop a system that will use virtual private network of the work organization and it will be secure because it will use SSL. So, we have to develop secure communication system. A central repository will be developed in which the stages of development of the project will be maintained on daily basis. The power will be distributed according to role for example administrator had full power to administer the development.

\section{NUMBERS AND DESCRIPTION OF MODULES}

LOGIN MODULE: -

This process logins and registered user by verifying username and password and OTP verifying with those user details stored in login table, if they do not match correct then error message is generated otherwise user is allowed to work in specified field in the particular project.

\section{ADMINISTRATION MODULE: -}

This process is used to perform work related to administration of the project. Only administrator is allowed to login in this module for all the projects running in the company. Various tasks performed in this modules are creating user, create project, create roles and assign user to project and he also has power to modify or delete above mentioned work.

\section{PROJECT MANAGEMENT MODULE: -}

This process is used to perform activities related to project management of the project. In this module project is divide into different categories like design, coding, testing etc. Only project manager and higher Authorities above him are allowed to login in this module. Various tasks performed in this module are creating categories, assigning project specific work to user, checking daily progress report and creating project status sheet.

\section{USER MODULE: -}

This process is used to perform activities related to the work assigned to the user of particular project. All users are allowed to login in this module by verifying username and password. Various activities performed by user in this module are read announcement and post his comment by user, the user upload files in specific areas he is authorized and the user has to fill daily progress report.

\section{GENERAL ANNOUNCEMENT MODULE: -}

This process is used to make announcements with the help of clipboard. The announcements are broadcast to all the users. Users have facility to read the announcement and post his comments.

ISSN: 2582-4104 
Journal of trends in Computer Science and Smart technology (TCSST) (2020)

Vol.02/ No. 04

Pages: 211-219

https://www.irojournals.com/tcsst/

DOI: https://doi.org/10.36548/jtcsst.2020.4.006

\section{FORUM MODULE: -}

This process is used to make for discussion. The forum may be General, technical, project specific. Question can be asked in this process, and answer can be posted to that question and again another question can be asked to that answer, also separate question can be asked.

\section{INFORMATION DESCRIPTION OF ADMINISTRATION MODULE: -}

This software intends to make management of project work easier. In this module the administrator will have all the privileges that of project managers and other users. The administrator can also keep track of progress made in different project running in the organization.

The administrator will have the privileges to check the work of every user on daily basis. Only administrator can modify or update the information about various user and project.

External system interfaces: The external system interfaces include the interfaces with human or with other systems.

Human interface: In this system there are human interfaces at two levels. One is with the user who interacts at the client site. The other is with the administrator who interacts at the server site.

Network interface: As the client and server will communicate over network, using existing technologies.

Database interface: This system will have to interact with databases, as it provides the user query to the database and sends back the result to the user (8).

Operating System: This system will depend on operating system for almost all its requirements like Primary Memory, CPU, Secondary storage etc. (7).

\section{INFORMATION DESCRIPTION OF ANNOUNCEMENT MODULE MENU: -}

The menu will be displayed according to role of person in the different projects. Only administrator can have full access to the menu. The menu will be derived from the database according to privileged assigned in the control_list table.

\section{FUNCTIONAL DESCRIPTION OF ADMINISTRATION MODULE: -}

A brief idea about the role the of administrator is supposed to do for project control and management. These are as follows: -

1. The administrator can create user to the project.

2. Only the administrator can create a new project.

3. The administrator can assign user to the project.

4. The administrator can create new roles as required by the projects.

5. Only the administrator can assign privileges to the roles.

6. The administrator can only modify or update the details of user, project, roles and privileges.

FUNCTIONAL DESCRIPTION OF ANNOUNCEMENT MODULE MENU: -

The menu should be displayed according to the role of the person. The administrator can have access to whole menu, the project manager has access to menu only to the project he is concerned, the user will have access to the specific task they are assigned(5).

ISSN: 2582-4104 
Journal of trends in Computer Science and Smart technology (TCSST) (2020)

Vol.02/ No. 04

Pages: 211-219

https://www.irojournals.com/tcsst/

DOI: https://doi.org/10.36548/jtcsst.2020.4.006

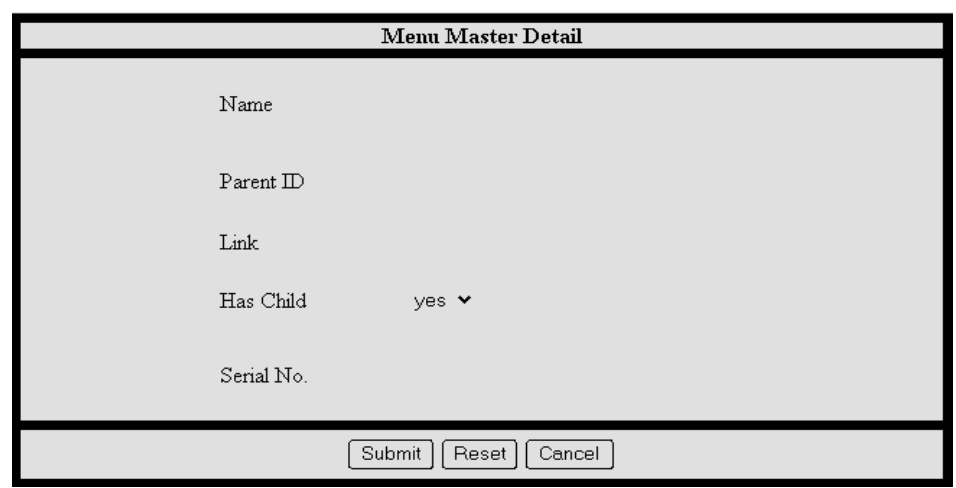

Figure 2

\section{PROJECT DESIGN CASES FORM: -}

This form is used to fill detail of the design type. The text boxes named 'last modified on' is filled to show the date of last modification and 'path' is used to specify the path where file is saved (3).

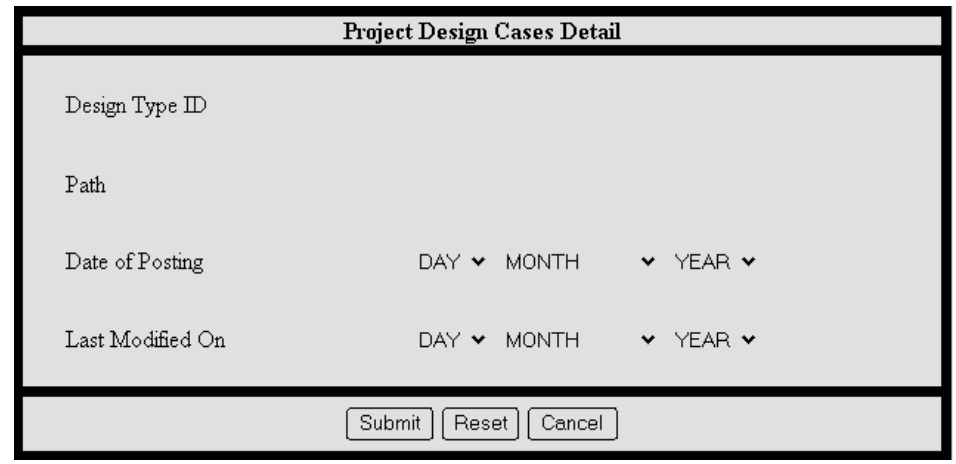

Figure 3

\section{PROJECT MASTER FORM: -}

This form will be used to fill detail of the project. Text box description will contain the objective of the project. Text label Project D.O.I means projects date of initiation and Project E.D.O.F means expected date of finish.

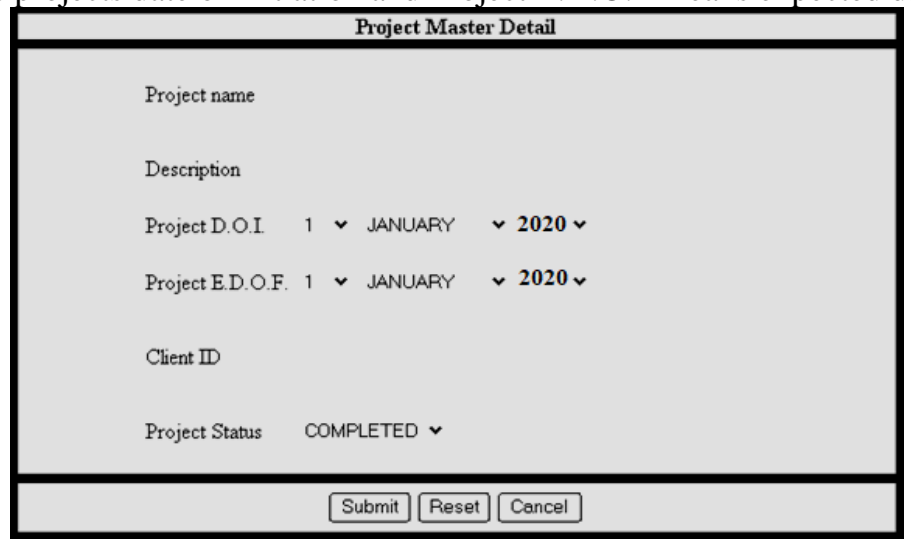

Figure 4 
Journal of trends in Computer Science and Smart technology (TCSST) (2020)

Vol.02/ No. 04

Pages: 211-219

https://www.irojournals.com/tcsst/

DOI: https://doi.org/10.36548/jtcsst.2020.4.006

\section{PROJECT MODULE FORM: -}

This form is used to fill detail of the modules created. Expected Date of Start and Expected Date of Finish are also filled, to calculate expected time taken by the module to complete.

\section{TOOLS AND PLATFORM USED}

\section{System Requirements: -}

$\Rightarrow$ Window dual core or more above

$\Rightarrow 2$ GB Random access memory or More

$\Rightarrow 4$ GB Server Random access memory

$\Rightarrow 128 \mathrm{~GB}$ Hard Disk Drive

$\Rightarrow 160$ GB Server Hard Disk Drive

\section{Software Requirements: -}

$\Rightarrow$ Windows /Linux sever

$\Rightarrow$ Apache Tomcat

$\Rightarrow$ MySQL or Oracle

$\Rightarrow$ Internet explorer

$\Rightarrow$ JDK 1.8

\section{Menu master: -}

This table is used to store information about various menus in the project. The column parent_id has value according to the level in which it lies. If main menu has sub menu, then column has child will have some value (2).

Table 1

\begin{tabular}{|c|c|c|c|}
\hline COLUMN NAME & TYPE & SIZE & ATTRIBUTES \\
\hline user_id & varchar2 & 6 & PRIMARY KEY \\
\hline user_name & char & 15 & NOT NULL \\
\hline user_designations & char & 15 & NOT NULL \\
\hline user_doj & date & & NOT NULL \\
\hline user_add_c & varchar2 & 25 & NOT NULL \\
\hline user_add_p & varchar2 & 25 & NOT NULL \\
\hline user_dob & date & & NOT NULL \\
\hline user_phone_no & number & 12 & \\
\hline user_mobile_no & number & 12 & \\
\hline user_email_id & varchar2 & 15 & NOT NULL \\
\hline user_dept_id & varchar2 & 6 & \\
\hline
\end{tabular}

\section{Role_master:-}

This table is used to store information about different roles available in any project. Various roles may be Administrator, Project manager, Team leader, coder, designer etc. Column role_status will be Boolean type which will only use to known whether the role is active or not.

Table 2

\begin{tabular}{|c|c|c|c|}
\hline COLUMN NAME & TYPE & SIZE & ATTRIBUTES \\
\hline role_id & varchar2 & 6 & PRIMARY KEY \\
\hline role_name & Char & 15 & NOT NULL \\
\hline role_status & char & 1 & \multirow{2}{*}{ CHECK (role_status IN('y','Y','n','N')) } \\
\hline
\end{tabular}

ISSN: 2582-4104 
Journal of trends in Computer Science and Smart technology (TCSST) (2020)

Vol.02/ No. 04

Pages: 211-219

https://www.irojournals.com/tcsst/

DOI: https://doi.org/10.36548/jtcsst.2020.4.006

Control_list:- This table is used to store information about role assigned to particular user in any particular project. Roles assigned to a user can be known through user_id in a particular project. Both user_id and role_id is foreign key reference of user_master and role_master respectively (1).

Table 3

\begin{tabular}{|c|c|c|c|}
\hline COLUMN NAME & TYPE & SIZE & ATTRIBUTES \\
\hline ct_id & varchar2 & 6 & PRIMARY KEY \\
\hline user_id & varchar2 & 6 & $\begin{array}{c}\text { Foreign key REFERENCES } \\
\text { user_id of user_master }\end{array}$ \\
\hline role_id & varchar2 & & $\begin{array}{c}\text { Foreign key REFERENCES } \\
\text { role_id of role_master }\end{array}$ \\
\hline
\end{tabular}

\section{TEST CASE DESIGN}

1. The login process logins already registered customers by verifying username and password. To test the login process once correct user name and password are provided for already registered user and checked whether login process successfully executes or not. Then incorrect username and passwords are entered and the outcome is seen.

2. Logout process is used for logging out already logged in user. Logout process is checked by logging out and then again navigating pages to check the pages if the information entered are still available. After logging out the cart entries and bill information should be null.

3. The menu displayed in the project should be role based. Various types of roles are defined and then they are given privileges in the menu and different login_id were tried to know whether proper menu displayed for the proper role of login person.

4. Proper care had been taken so that no one can access any page directly through web browser. So, every page is called directly from web browser to know whether they are displayed or not.

5. In announcement module no user can read other users announcement as well as can't delete other user's announcement. So, it is tried from all login user session to read or delete other user's announcement.

There are three stages in an implementation process: -

$\Rightarrow$ Training Personnel

$\Rightarrow$ Application Conversion Procedure

$\Rightarrow$ Post Implementation Review

a) Training Personnel: Running of the system successfully depends on the user of the computer software. Training the users includes basic operability features such as rules and regulations for operating the software to optimum benefit. It is a feature where a line is drawn showing the similarities between the existing system and the new system. The user is shown the benefits which now he gets through a computerized process. This helps in easy adaptability to the new system by the users.

The emphasis is on showing the linkages between the present and the new system to the user. This helps in better understanding of the new system Successful culmination of training means that the user has a better understanding of the new system vis-à-vis the older one and the benefits the newer one offers over the older one.

b) Application Conversion Procedure:

Parallel System: This is the safest method for converting the system from old to new one. consumers are operating the preview systems in the continue manner but they are providing the new system alongside. The function is secure one because it ensures that in case of any problems during the real time operations of the new system, the manager can resolve the problems.

ISSN: 2582-4104 
Journal of trends in Computer Science and Smart technology (TCSST) (2020)

Vol.02/ No. 04

Pages: 211-219

https://www.irojournals.com/tcsst/

DOI: https://doi.org/10.36548/jtcsst.2020.4.006

c) Implementation Review: Afterwards the system is implemented and installed the new version is complete the review plan is conducted to determine or the system is meeting confidence and where improve system are needed. System is measured against pre-defined requirements. Thorough study is done to determine whether the new system requires re-designing or not. Information required for it, begins with the review plan, during which the user views are kept into consideration.

Maintenance is the main part of the project development life cycle. It's indeed the implementation of the post- review plan. it's a need to continually maintain the Project, which includes among other a regular performance tuning of the database. The maintenance part of the system life cycle is less required if sufficient time has been given during the analysis phase of the system.

Researches show that only 19\% of all maintenance works is spent for Corrective Maintenance. The remaining $81 \%$ is spent adapting existing Projects to changes in the internal environment, and develop an application for next time use, also called Adaptive Maintenance.

The software is using to the user will declare additional methods that will provide benefits.

Considering human psyche performing Perceptive Maintenance will be highly required.

\section{FUTURE OPPORTUNITY OF THIS PROJECT}

The future scope of the project may be very wide; few scope is defined below: -

1. This project can be developed as Integrated Development Environment (IDE) that is designing, coding and testing can be done on same project, by integrating various development tools like visual source.

2. This project can handle more than one project simultaneously.

3. Roles of user in various projects can be displayed automatically as he logs in.

4. This project can be used to run in Virtual Private Network of an organizations using SSL.

5. More authentication, responsibilities can be added to existing system.

Besides these features, various other features may also be added which are not uncovered yet, in the existing system for enhancing its functionality.

\section{REFERENCES}

[1] PL/SQL by Ivan Bayross.

[2] Oracle 8i Complete Reference from Oracle Press

[3] System Analysis and Design by Elias M. Edward

[4] Software Engineering a Practitioner Approach by Roger S. Pressman.

[5] Professional JSP from WROX Press.

[6] Complete Reference JAVA 2 from TMH.

[7] Poonam S. Patih, and Rajesh, N. Phursule "Survey Paper on Big Data Processing and Hadoop Components".

[8] Konstantin Shvachko, Hairong Kuang, Sanjay Radia, Robert Chansler, "The Hadoop Distributed File System" @ yahoo_inc.com

ISSN: 2582-4104 